\title{
The Positive and Negative Framing of Affirmative Action: A Group Dominance Perspective
}

\section{Citation}

Haley, Hillary, and James Sidanius. 2006. The positive and negative framing of affirmative action: A group dominance perspective. Personality and Social Psychology Bulletin 32, no. 5: 656-668.

\section{Published Version}

http://dx.doi.org/10.1177/0146167205283442

\section{Permanent link}

http://nrs.harvard.edu/urn-3:HUL.InstRepos:3205412

\section{Terms of Use}

This article was downloaded from Harvard University's DASH repository, and is made available under the terms and conditions applicable to Other Posted Material, as set forth at http:// nrs.harvard.edu/urn-3:HUL.InstRepos:dash.current.terms-of-use\#LAA

\section{Share Your Story}

The Harvard community has made this article openly available.

Please share how this access benefits you. Submit a story.

Accessibility 


\section{Personality and Social Psychology Bulletin}

http://psp.sagepub.com

The Positive and Negative Framing of Affirmative Action: A Group Dominance Perspective Hillary Haley and Jim Sidanius

Pers Soc Psychol Bull 2006; 32; 656

DOI: $10.1177 / 0146167205283442$

The online version of this article can be found at: http://psp.sagepub.com/cgi/content/abstract/32/5/656

Published by:

(9)SAGE

http://www.sagepublications.com

On behalf of:

SP

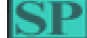

Society for Personality and Social Psychology, Inc.

Additional services and information for Personality and Social Psychology Bulletin can be found at:

Email Alerts: http://psp.sagepub.com/cgi/alerts

Subscriptions: http://psp.sagepub.com/subscriptions

Reprints: http://www.sagepub.com/journalsReprints.nav

Permissions: http://www.sagepub.com/journalsPermissions.nav

Citations http://psp.sagepub.com/cgi/content/refs/32/5/656 


\section{The Positive and Negative Framing of Affirmative Action: A Group Dominance Perspective}

\author{
Hillary Haley \\ Jim Sidanius \\ University of California, Los Angeles
}

Using a sample of 328 White, Latino, and Black Los Angeles County adults, the authors examined the tendency to employ various affirmative action "frames" (e.g., affirmative action as a "tie-breaking" device or as a quota-based policy). All three groups agreed about which frames cast affirmative action in a positive light and which cast it in a negative light. Although minorities had a tendency to frame affirmative action in terms that most people find morally acceptable, Whites had a tendency to frame affirmative action in terms most people find unacceptable. In addition, compared to minorities, Whites were less supportive of affirmative action regardless of how it was framed. LISREL modeling also was employed to test two competing models regarding predictors of the tendency to use frames that one personally finds to be relatively negative versus positive. Consistent with the expectations of social dominance theory and a motivated cognition perspective, the authors found that social dominance orientation (SDO) had significant net direct and indirect effects on one's framing of affirmative action.

Keywords: affirmative action; framing effects; motivated reasoning; social dominance theory; social dominance orientation

$\mathbf{P}$ recisely what do people mean when they use the term "affirmative action"? Are people typically referring to outreach and training programs for disadvantaged groups, to admissions and hiring policies that simply take applicants' group memberships into consideration, or to pure quota-based initiatives? Just as there are a great many programs and policies designed to take affirmative action on behalf of different groups, there are also many different ways that people can interpret the term when reflecting on, and making judgments and decisions about, things having to do with affirmative action in general. Because people's interpretations in turn tend to reinforce their preexisting attitudes, and serve as fil- ters for new, incoming information (e.g., see Fazio, 1990), it is essential, in studying affirmative action, to understand exactly what people's interpretations are and where they come from.

Much research in social and political psychology has explored the questions of whether and why people support affirmative action as a general practice and whether and why they support specific group-targeted policies in particular. Such research has consistently shown that support varies as a function of respondents' political orientation (with liberals being more supportive than conservatives; e.g., Aberson \& Haag, 2003; Sidanius, Pratto, \& Bobo, 1996), as a function of respondents' racial/ ethnic group (with minorities being more supportive than Whites; e.g., Kinder \& Sanders, 1996; Kluegel \& Smith, 1986), and as a function of the framing and/or details of the policy under consideration (e.g., Bell, Harrison, \& McLaughlin, 2000; Fine, 1992; Kinder \& Sanders, 1990). Notably, though, far less research has examined how people actively construe, or frame, the term "affirmative action" themselves; that is, although we know a lot about people's responses to scripted versions of affirmative action cases, we know relatively little about why people, when thinking about affirmative action on their own, tend to frame it in particular ways.

The research presented in this article aims to replicate past work on affirmative action preferences and to meaningfully build on that past work by examining how

\footnotetext{
Authors' Note: Please address correspondence to Jim Sidanius, University of California, Los Angeles, Department of Psychology, 405 Hilgard Avenue, Los Angeles, CA 90095-1563; e-mail: sidanius@psych.ucla .edu.

PSPB, Vol. 32 No. 5, May 2006 656-668

DOI: $10.1177 / 0146167205283442$

(C) 2006 by the Society for Personality and Social Psychology, Inc.
} 
and why people frame affirmative action in idiosyncratic ways.

\section{Effects of Issue Framing on Affirmative Action Attitudes}

Past research has repeatedly shown that the popularity of affirmative action programs can radically rise or decline depending on how the term "affirmative action" is framed and/or what specific policy is under consideration (e.g., Bell et al., 2000; Bobo \& Kleugel, 1993; Bobo \& Smith, 1994; Fine, 1992; Kinder \& Sanders, 1990; Kravitz, 1995; Schuman, Steeh, Bobo, \& Krysan, 1997; Sniderman \& Carmines, 1997; Summers, 1995). For example, Bobo and colleagues (e.g., Bobo \& Kleugel, 1993; Bobo \& Smith, 1994) have shown that people are more supportive of "opportunity-enhancing" forms of affirmative action than of "outcome-directed" forms. Similarly, Sniderman and Carmines (1997) found that White Americans were more partial to affirmative action when it was framed in terms of making extra efforts to achieve equal treatment of groups rather than in terms of giving preferential treatment to certain groups (see also Summers, 1995). Furthermore, Kravitz and Klineberg (2000) found that both Whites and Blacks were more supportive of "typical" affirmative action policies when they believed that typical meant the absence of preferential treatment. Unsurprisingly, it also has been shown that people are rather unsupportive of quota-based programs and of programs stipulating clear-cut racial preferences (e.g., Schuman et al., 1997).

Similarly, support for affirmative action has been shown to depend on the real or supposed characteristics of potential recipients and related contextual factors. For example, in a recent experimental study, Quinn, Ross, and Esses (2001) found that college students' endorsement of affirmative action programs varied depending on whether the students believed (a) that recipient groups were responsible for their disadvantages and (b) that recipient groups were responsible for solving present predicaments "on their own." Along similar lines, Son Hing, Bobocel, and Zanna (2002) found that when people perceived workplace discrimination, they became increasingly supportive of affirmative action programs.

Murrell, Dietz-Uhler, Dovidio, Gaertner, and Drout (1994) have reported differing levels of support for affirmative action as a function of both policy framing and target group. These researchers looked at White college students' attitudes as a function of (a) whether a policy was presented with "social justification;" (b) whether the target group was Blacks, "the handicapped," or the elderly; and (c) whether the institutional context was a business, college, or social organization. It was found here that people were relatively more supportive when given the "socially justified" frame and relatively more supportive when the target group was "the handicapped" or the elderly (rather than Blacks). Consistent with this last finding, it is noteworthy that research also has found that White people who tend to associate affirmative action with Black and Hispanic target groups (rather than other target groups) also tend to have relatively negative affirmative action attitudes (Kravitz et al., 2000; Sidanius, Singh, Hetts, \& Federico, 2000).

The above literature indicates, in short, that people's responses to affirmative action fluctuate significantly across various "prepackaged" conceptualizations of the issue. At the same time, though, there are hints in the literature that people can and do use their own frames when interpreting information about affirmative action, for example by deploying particular storylines, catchphrases, and metaphors when thinking about the issue. Our notion of framing here, it should be noted, is very similar to what Fraser and Kick (2000), borrowing from Wetherell and Potter (1992), call "interpretive repertoires" and to what Nacoste and colleagues (Nacoste, 1994; Nacoste \& Hummels, 1994) term "cognitive schemas."

In relevant research conducted by Arriola and Cole (2001), White college students were asked to describe a specific affirmative action policy. Not only did different students describe policies that the authors classified as being based on fundamentally different definitions of affirmative action (i.e., quota-based policies, equalopportunity policies, and others) but an overwhelming $38 \%$ of students-despite having opinions about affirmative action-were unable to actually describe any single policy at all! These results very clearly indicate that different people operate with different understandings of what the term "affirmative action," in a general sense, might mean.

Furthermore, in research conducted by Golden, Hinkle, and Crosby (2001), White and minority adults were asked whether a policy of organizational monitoring or a policy of government-regulated quotas came closer to their personal understanding of affirmative action. Not only was there a blatant lack of consensus among the respondents (i.e., $54.3 \%$ indicated monitoring and $45.7 \%$ quotas) but the researchers additionally found that-even after accounting for demographic and associated attitudinal variables-the respondents who indicated monitoring were far more likely to support affirmative action than were the respondents who indicated quotas. These results provide a glint of evidence for one of the key ideas explored in this article: the idea that people tend to adopt those conceptualizations of affirmative action that best align with, or help to justify, their existing predilections. 


\section{The Motivated Social-Cognitive Perspective}

A large literature within social psychology attests to the fact that people's attitudes are dictated not just by their values, beliefs, and powers of logical reasoning but also by a more complicated set of conscious and unconscious personal motivations (e.g., self-enhancement) and social motivations (e.g., group dominance; e.g., see Duckitt, 2001; Dunning, 1999; Fiske \& Taylor, 1991; Greenwald, 1980; Kunda, 1990). Thus, although people may often feel that their attitudes and actions are completely unrelated to such psychological motivations, they may (unwittingly) work to satisfy such motivations by (a) selectively focusing attention on some situations or cases rather than others; (b) construing concepts or situations in idiosyncratic ways (i.e., using particular types of frames); (c) showing greater recall for some cases or situations than for others; and so on. As applied to political and policy attitudes, this perspective simply suggests-in the broadest terms-that personal and social motivations (in addition to cognitive factors) can make meaningful contributions to the way people think and behave politically (e.g., see Borowiak \& Golec, 2004; Jost, Glaser, Kruglanski, \& Sulloway, 2003; Redlawsk, 2002).

For example, in a recent meta-analysis examining 88 studies from a total of 12 different countries, Jost et al. (2003) provided compelling evidence that politically conservative worldviews are, at least in part, shaped by three large clusters of motivations: (a) epistemic motivations (e.g., motivations for uncertainty avoidance and cognitive closure); (b) existential motivations (e.g., motivations for self-esteem and terror management); and (c) ideological motivations (e.g., motivations for system justification and group dominance). In line with these meta-analytic findings, Borowiak and Golec (2004) recently reported evidence for associations between the need for cognitive closure and traditional and modern (as opposed to postmodern) worldviews-again suggesting that conservatism is affected by (in this case epistemic) psychological motivations. Importantly, though, it should be observed that all of these researchers also emphasize that people do often behave rationally-by attempting to gather trustworthy information about political issues, for example-and do often rely on beliefs, values, and logical reasoning when forming their views. They are simply calling attention to the fact that motivational factors can also play extremely important roles.

Following from this motivated social-cognitive perspective is the idea that psychological motivations will partially determine not just people's levels of support for affirmative action but also the ways in which people actively construe, frame, or think about affirmative action. That is, those who are motivated to oppose affirmative action also should be motivated to view the construct in relatively repellant terms (terms that justify opposition), whereas those who are motivated to support affirmative action also should be motivated to view the construct in relatively favorable terms (terms that justify support).

One set of ideological factors that may affect the manner in which people frame the issue of affirmative action is political conservatism. A good deal of empirical evidence suggests that those with conservative political values object to affirmative action because it is perceived to violate widely accepted norms of individual effort, fairness, and equity (e.g., see Sidanius et al., 2000; Sniderman \& Piazza, 1993). Because of these largely political and normative objections to affirmative action, there is good reason to expect that those holding conservative political values also will be motivated to construe and frame affirmative action in terms that most people will find objectionable. Along the same lines, beliefs in the Protestant work ethic (e.g., the belief that success in U.S. society primarily results from individual merit), which should be associated with conservatism and with general opposition to affirmative action, also should be predictive of affirmative action framing tendencies. Supporters of the general group dominance perspective, however, would argue that this is not the end of the story; instead, they would argue that in addition to conservative beliefs, motives for group dominance will play a significant role in predicting people's framing.

\section{The Group Dominance Perspective}

The general group dominance perspective can be said to consist of a cluster of relatively recently developed theories of intergroup relations, including group positions theory (Blumer, 1958; Bobo, 1999), models of paternalistic oppression (e.g., Jackman, 1994; van den Berghe, 1967), realistic group conflict theory (Sherif, 1966), and social dominance theory (Sidanius \& Pratto, 1999). Despite some important differences between these various theories, all of them are premised on three important observations. The first observation is that virtually all modern societies are organized hierarchically, such that some groups of people are relatively dominant (enjoying disproportionate access to material and symbolic resources such as property and prestige), whereas other groups are relatively subordinate (suffering disproportionate subjugation to material and symbolic disadvantages). Second, it is observed that political attitudes and behaviors, especially those concerning the allocation of resources, are largely manifestations of group competition. Third, it is observed that dominant groups, and to a lesser extent subordinate groups as well, endorse legitimizing myths_-"attitudes, values, beliefs, or ideologies that provide moral and intellectual support to and justification for the group-based hierarchical social structure and the unequal distribution of value in 
social systems" (Sidanius, 1993, p. 207). Beliefs in racial inferiority, in a "just world," in political conservatism, and in the Protestant work ethic can all be considered legitimizing myths because all of these beliefs serve to justify and reinforce existing social hierarchies and have been shown to be related to desires for group dominance and hierarchically structured social relationships (see Sidanius, Levin, Federico, \& Pratto, 2001; Sidanius \& Pratto, 1999).

A series of predictions follow from these observations with respect to political attitudes in general and affirmative action attitudes in particular. Specifically, proponents of social dominance theory argue that a central motivator behind people's affirmative action attitudes is social dominance orientation (SDO) - a generalized tendency to support existing hierarchical relationships among groups (Pratto, Sidanius, Stallworth, \& Malle, 1994; Sidanius, Liu, Shaw, \& Pratto, 1994; Sidanius \& Pratto, 1999). This is because, relative to people who are low in SDO, those who are high in SDO are expected to favor ideologies that work to maintain and/or heighten existing hierarchical relations (e.g., political conservatism, ethnic/racial prejudice), and opposition to affirmative action is thought to be one such ideology. Furthermore, although it is recognized that political conservatism and endorsement of Protestant work ethic beliefs (e.g., the belief that success in U.S. society is primarily due to individual merit) are part of what drives affirmative action attitudes, it also is expected-because these beliefs are thought to function as legitimizing ideologies-that they will act as mediators through which SDO exerts effects; that is, in addition to affecting affirmative action attitudes directly, SDO is expected to affect affirmative action attitudes indirectly as well via its associations with political conservatism and Protestant work ethic beliefs.

There is a substantial amount of research supportive of the social dominance framework. To begin with, it has been demonstrated that SDO is significantly correlated with racism and with attitudes toward race-targeted policies such as affirmative action. It also has been shown that political conservatism is associated with SDO, racism, and attitudes toward race-targeted policies (e.g., Pratto et al., 1994). In addition, Federico and Sidanius (2002) found that the tendency to endorse principled objections to affirmative action policies was driven not merely by race-neutral values but also by dominancerelated concerns such as racism. Moreover, these researchers found, as anticipated, that endorsement of these objections mediated the effects of group dominance. Furthermore, working quite independently of social dominance researchers, Fraser and Kick (2000) have suggested that group dominance motives are likely to play a critical role in how people frame affirmative ac- tion. In their research, using discourse analysis, it was found that participants who were most opposed to affirmative action and most likely to define it as blatantly and unqualifiedly unfair were also those who were most likely to endorse a stratification ethos-believing, essentially, that groups with low social status deserved to be precisely where they were. In the present research, we expand on this past work by empirically examining the role that SDO plays in driving people's tendencies to use particular types of affirmative action frames.

\section{The Current Research}

The present research seeks to advance existing knowledge of how people construe affirmative action and to explore why they might construe it in different ways. In this research, we will examine public opinion among adult Whites, Blacks, and Latinos about six different frames as well as information about how often respondents tend to think about affirmative action in each of these six ways.

The frames used in this research were generated from informal focus groups and are representative of the different kinds of frames that emerge in discourse analyses (e.g., Fraser \& Kick, 2000). They are: providing training to underrepresented groups, engaging in outreach to recruit members of certain groups, considering group membership as "one factor among many," using group membership as a "tie-breaking" device, using quotas, and giving preferences to (relatively) underqualified applicants.

Four substantive questions will be addressed in this article. First, we will examine whether there are significant differences between ethnic groups in their pattern of support versus opposition to different affirmative action frames. Previous research using White samples has shown that opposition is relatively weak when affirmative action is framed in terms of training or outreach and relatively strong when it is framed in terms of quotas or preferring underqualified applicants (e.g., Bell et al., 2000; Bobo \& Kluegel, 1993; Bobo \& Smith, 1994; Fine, 1992; Kinder \& Sanders, 1990; Kravitz, 1995; Schuman et al., 1997; Sniderman \& Carmines, 1997; Summers, 1995). Because there is no reason to suppose that this same general pattern of support versus opposition will differ for Whites versus Latinos or Blacks, we expect that all three groups will show the same pattern-in effect, agreeing on which frames make affirmative action "look good" and which frames don't.

Second, although all ethnic groups are expected to show the same general pattern of support versus opposition across the different frames, it is expected, in line with the general group dominance model, that there will be a main effect for race/ethnicity, regardless of which frame is used. This is to say that because all forms of affir- 
mative action are directed at narrowing socioeconomic gaps between ethnic and racial groups, members of the dominant ethnic group (i.e., Whites) should always be more opposed to affirmative action than members of subordinate ethnic groups (i.e., Blacks and Latinos), regardless of how this social policy is framed.

Third, again following from the general group dominance perspective and, more broadly, the motivated social-cognitive perspective, it is expected that Whites also will be relatively more likely than minorities to use negative frames (i.e., those that are seen as most objectionable by respondents in general) rather than positive frames (i.e., those that are seen as least objectionable by respondents in general). In other words, we expect that Whites will be relatively more likely than minorities to think about affirmative action in terms of quotas and preferences for underqualified applicants (anticipated to be the most opposed frames) and relatively less likely to think about affirmative action in terms of training and outreach (anticipated to be the least opposed frames). Similarly, we anticipate that Whites will be relatively more likely than minorities to think about affirmative action in ways that they personally judge to be unflattering rather than flattering.

Finally, again following from the motivated socialcognitive and group dominance perspectives, we expect that-above and beyond the effects of race/ethnicityboth conservative ideologies (political conservatism and Protestant work ethic beliefs) and SDO will influence this tendency for people to frame affirmative action in ways they find personally objectionable.

\section{METHOD}

\section{Respondents}

Data for this research come from the 1996 Los Angeles County Social Survey (LACSS), conducted every year by the Institute for Social Science Research (ISSR) at the University of California, Los Angeles (UCLA). The LACSS is a large omnibus survey of the residents of Los Angeles County assessing approximately 200 variables, including such things as standard demographics, feeling thermometers concerning various social groups, general attitudes regarding race/ethnicity, political ideology, and support for policies targeted toward various social groups. The 1996 sample consisted of 706 adults randomly selected from Los Angeles County during the spring of 1996. This sample was composed of 206 Whites, 209 Blacks, 43 Asians, 205 Latinos, and 43 individuals whose racial/ethnic categorization was Other or missing (note that Latino and Black populations were oversampled). For the present analyses, only U.S. citizens identifying as White, Black, or Latino were used, leaving an effective sample size of 328 (151 Whites, 129 Blacks, and 48 Latinos).

\section{Sampling Procedure}

The survey was conducted by the Computer Assisted Telephone Interviewing unit of the ISSR using a random digit dial telephone technique. Interviews were conducted by regular ISSR interviewing staff and by students from an undergraduate survey research methods course who had received 12 hours of interviewing training. To maximize sample representativeness, the survey made use of a 12-attempt callback procedure and systematically varied callback day and time. The survey had a lower-bound response rate estimate of $45 \%$ and an upper-bound estimate of $55 \%$. Within each racial/ethnic group the distribution of sample characteristics on key social background factors (e.g., native-born status, education, sex, age, household income, occupation) closely resembled that obtained by the 1990 Census for Los Angeles County (see Bobo, Johnson, Oliver, Sidanius, \& Zubrinsky, 1992, for details). In addition, a systematic analysis of potential nonresponse bias, based on the procedure developed by O'Neil (1979), indicated that no significant nonresponse bias was present (Greenwell, Strohm, \& Bobo, 1994).

\section{Variables}

Demographics. Demographic variables included (a) age, $($ b) gender $($ men $=1$, women $=2)$, $($ c) education (measured on a 6-point scale from $1=$ did not graduate from high school to 6 = earned a graduate degree), and (d) estimated household income.

Political conservatism. Political conservatism was assessed with a composite measure based on seven indices. The indices consisted of (a) a 5-point scale indexing political party preference $(1=$ strong Democrat to $5=$ strong Republican), (b) a 5-point political self-description scale $(1=$ very liberal to $5=$ very conservative $)$, (c) a 4-point scale assessing agreement with the statement, "The government should guarantee that basic health care is available for all Americans" ( $1=$ strongly agree to $4=$ strongly disagree), (d) a 4-point scale assessing agreement with the statement, "The government should lower taxes" $(1=$ strongly disagree to $4=$ strongly agree), (e) a 4-point scale assessing agreement with the statement, "The government has taken over too many things that should be handled by individuals, families, and private businesses" $(1=$ strongly disagree to 4 = strongly agree), (f) a 4-point scale assessing agreement with the statement, "The government should be actively involved in solving problems that develop between groups, businesses, and individuals" ( $1=$ strongly agree to $7=$ strongly disagree), and $(\mathrm{g})$ a 4-point scale assessing agreement with the statement, "The government should reduce its assistance to the poor" $(1=$ 
strongly disagree to 4 = strongly agree). The final measure of conservatism consisted of the sum of the standardized scores for the seven questions (Cronbach's $\alpha=.66$ ).

Success and individual effort. This construct was measured with respondents' responses regarding the statement, "Success, or one's achievement in American society, depends primarily on individual merit." Responses to this item were measured on a 4-point scale ( 1 = strongly disagree to $4=$ strongly agree) .

Social dominance orientation (SDO). SDO was assessed using the complete 16-item Social Dominance Orientation Scale (Cronbach's $\alpha=.80$; see Sidanius \& Pratto, 1999). All items were assessed on a 4-point response scale ( ranging from $1=$ strongly agree to $4=$ strongly disagree) . Respondents' final SDO scores were determined by reverse-coding the necessary items and then taking the scale mean (see Sidanius \& Pratto, 1999). High values on this scale are reflective of a high social dominance orientation, whereas low values are reflective of a low social dominance orientation.

Tendencies to use specific affirmative action frames. The manner in which people themselves tended to frame affirmative action was assessed by first reading the following introductory paragraph to each respondent:

People have different ideas about what affirmative action is. I am going to give you a number of ideas people have about it. For each one I would like you to tell me if this is what $Y O U$ think of when I say "affirmative action."

Respondents were then given the six frames: (a) "Quotas, that is, setting aside places for certain groups"; (b) "Using group membership as one of several considerations"; (c) "Using membership in certain groups as a tie-breaker when applicants are equally qualified"; (d) "Giving training to certain groups so they can compete equally"; (e) "Making a special effort to find qualified people from certain groups"; and (f) "Giving preference to members of certain groups who are less qualified than someone else." After each frame was read, respondents were asked to indicate the degree to which they personally tended to think about affirmative action that way using a 3 -point scale $(1=$ not at all, $2=$ often, $3=$ very often $)$. The order in which the six definitions were read was randomized across respondents.

Opposition to specific affirmative action frames. Respondents were then asked to indicate the degree to which they supported or opposed affirmative action as defined by each of the six frames. An introduction to this series of questions read as follows:

Now, something a little different. I'd like you to tell me how you personally feel about different kinds of affirma-

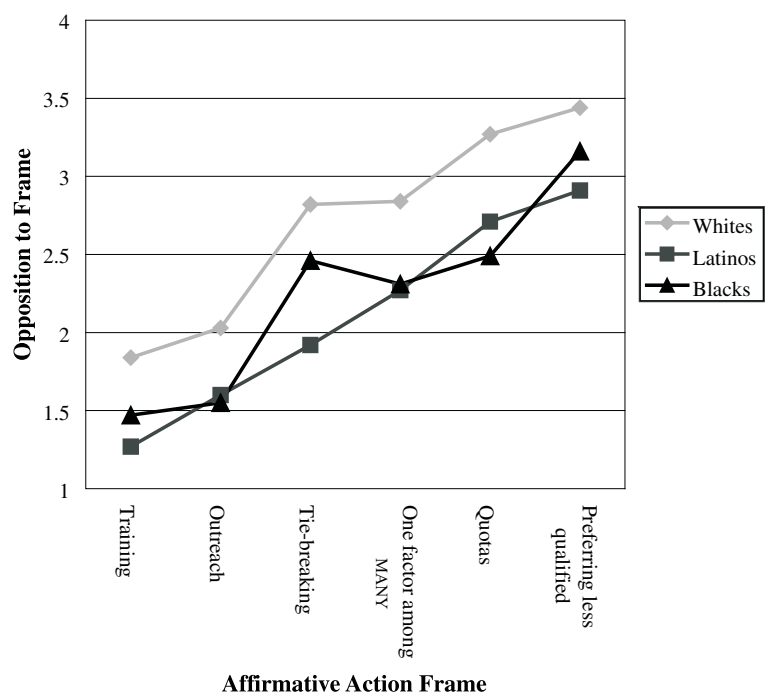

Figure 1 Mean opposition to each of six different affirmative action frames, by respondent race/ethnicity.

tive action. For each of the following policies, please tell me if you strongly support, somewhat support, somewhat oppose, or strongly oppose the policy.

After each definition was read for the second time, respondents indicated their degree of opposition using a 4 -point scale $(1=$ strongly support the policy to $4=$ strongly oppose the policy). Once again, the order in which the policies were presented was random.

\section{RESULTS}

\section{Opposition to Specific Frames}

The first substantive question concerned whether affirmative action attitudes depended on framing and/or respondents' race/ethnicity. To explore this question, we performed a two-way analysis of variance with repeated measures over one factor. Race/ethnicity served as the between-subjects factor and type of affirmative action frame served as the within-subjects factor.

The results of this analysis showed that opposition to affirmative action was significantly affected by frame; Frame: $F(5,1565)=155.52, p<.001, \eta=.58$. As can be seen in Figure 1, people were most opposed to affirmative action when it was defined in terms of quotas ("Quotas, that is, setting aside places for certain groups") and-especially—when it was defined in terms of hiring relatively less-qualified people ("Giving preference to members of certain groups who are less qualified than someone else"). In contrast, people were most in favor of affirmative action when it was defined in terms of train- 
ing ("Giving training to certain groups so they can compete equally") and outreach ("Making a special effort to find qualified people from certain groups"). Intermediate attitudes occurred when affirmative action was defined in terms of tie-breaking or in terms of considering group membership as "one factor among many."

Although there was a small interaction between respondents' race/ethnicity and frame in predicting attitudes; Frame $\times$ Race $/$ Ethnicity: $F(10,1565)=2.85, p<$ $.01, \eta=.13$, the data also showed, as expected, that all three racial/ethnic groups exhibited the same general pattern of opinions across frames (i.e., the groups converged on a common notion of which frames were relatively worthy of support and which were relatively objectionable). To quantify this pattern of convergence, we correlated the mean ratings (for the various frames) across the three groups. This analysis revealed a very high degree of pattern similarity across the three groups; Whites-Latinos: $r=.972, p<.01$; Whites-Blacks: $r=.961$, $p<.01$; Blacks-Latinos: $r=.914, p<.01$.

In addition, the data in Figure 1 seem to imply that the six affirmative action frames can be roughly classified into three categories, each consisting of two frames: (a) relatively negative frames (i.e., the use of quotas, preferences for less-qualified candidates), (b) intermediate, or neutral, frames (i.e., the use group membership as "one factor among many," the use of group membership as a "tie-breaker"), and (c) relatively positive frames (i.e., training certain groups so they can compete equally, making a special effort to find qualified people from certain groups).

Despite the fact that there was very strong agreement across race/ethnicity concerning which forms of affirmative action are more or less objectionable, there was also, consistent with our second hypothesis, a clear and relatively strong main effect for race/ethnicity; Race/ Ethnicity: $F(2,313)=19, p<.001, \eta=.33$. Although post hoc comparisons (using the Scheffé method) showed no overall difference between Blacks and Latinos, Whites were significantly more opposed to affirmative action in general than either of these minority groups at the $p<$ .05 level and beyond. ${ }^{1}$

Furthermore, consistent with social dominance theory, contrast analyses revealed that Whites were more opposed to affirmative action than were minorities within each and every frame. As can be seen in Figure 1, even when affirmative action was framed in the terms that people find most acceptable (i.e., "Giving training to certain groups so they can compete equally"), Whites were still more opposed than minorities.

To further probe this White-minority difference, we again conducted analyses of variance but restricted analyses to the form of affirmative action that most people found the most objectionable (i.e., "Giving prefer- ence to members of certain groups who are less qualified") and the form that most people found the most acceptable (i.e., "Giving training to certain groups so they can compete equally"). We also combined Blacks and Latinos into a single, subordinate group. The question then became whether the degree of dominant/subordinate difference in opposition to affirmative action decreases as one moves from the most objectionable frame to the most acceptable frame. If this were indeed the case, we should expect a significant interaction between race/ethnicity and frame. However, the results of this analysis showed no such interaction; Framing $\times$ Race/ Ethnicity: $F(1,324)<1$. In other words, framing affirmative action in generally benign rather than noxious terms did essentially nothing to attenuate the dominant/subordinate group difference in opposition to affirmative action; this difference remained more or less constant regardless of framing.

\section{Tendencies to Use Specific Frames}

The next major question addressed was whether dominant and subordinate racial/ethnic groups have a tendency to frame the construct of affirmative action in specific different ways. Given the overall thesis of motivated social cognition, and given the general logic of the group dominance paradigm, we would expect that members of dominant groups (i.e., Whites) would tend to frame affirmative action in the terms that most people find objectionable (i.e., in terms of quotas and preferences for less-qualified candidates), whereas members of subordinates groups (i.e., Latinos and Blacks) would tend to frame affirmative action in terms that most people find acceptable (i.e., in terms of training and outreach). To examine this question, we performed another two-way analysis of variance with repeated measures over one factor. Race/ethnicity served as the between-subjects factor and type of frame served as the within-subjects factor.

The results of this analysis showed a slight main effect for frame, with participants tending to frame affirmative action in ways that - according to most people-are relatively positive (i.e., as training and outreach); Frame: $F(5,1570)=5.72, p<.001, \eta=.13$. As can be seen in Figure 2 , the results of this analysis revealed no significant main effect for race/ethnicity, $F(2,308)<1$. Rather, there was a significant interaction between type of affirmative action frame and race/ethnicity; Frame $\times$ Race/ Ethnicity: $F(10,1570)=6.64, p<.01, \eta=.20 .^{2}$ To simplify the interpretation of Figure 2, note that we have arranged the various frames in terms of their general degree of perceived acceptability, from affirmative action as training (the most acceptable frame) to affirmative action as preferring less-qualified candidates (the most unacceptable, or objectionable, frame). As can be seen 
TABLE 1: Opposition to Six Different Affirmative Action Frames Regressed on Demographic Factors and Sociopolitical Values/Ideologies

\begin{tabular}{|c|c|c|c|c|c|c|}
\hline & \multicolumn{6}{|c|}{ Affirmative Action Framing } \\
\hline & \multicolumn{2}{|c|}{ Positive Frames } & \multicolumn{2}{|c|}{ Neutral Frames } & \multicolumn{2}{|c|}{ Negative Frames } \\
\hline & Training & Outreach & Tie-Breaking & "One Factor Among Many" & Quotas & $\begin{array}{c}\text { Preferences for } \\
\text { Less-Qualified Applicants }\end{array}$ \\
\hline \multicolumn{7}{|l|}{ Demographic factors } \\
\hline Income & .06 & .04 & .09 & .05 & $.16^{* *}$ & .03 \\
\hline Age & $.10 \dagger$ & .05 & .05 & .07 & .01 & .02 \\
\hline Education & -.05 & $.12^{*}$ & .09 & .03 & .04 & -.04 \\
\hline Female & -.06 & .02 & -.01 & -.02 & -.06 & -.05 \\
\hline White & $-.18 * * *$ & -.10 & -.03 & -.04 & $.12 *$ & $.20 * * *$ \\
\hline \multicolumn{7}{|l|}{ Values/ideologies } \\
\hline SDO & -.09 & -.04 & $.15^{*}$ & .02 & .04 & $.15^{*}$ \\
\hline Conservatism & -.06 & $-.12 *$ & -.00 & -.02 & $.11 \dagger$ & $.14^{*}$ \\
\hline Success and individual effort & -.02 & -.02 & .02 & .01 & .06 & .08 \\
\hline Adjusted $R^{2}$ & $.04 * *$ & $.03^{*}$ & $.02 \uparrow$ & .00 & $.07 * * *$ & $.12 * * *$ \\
\hline
\end{tabular}

NOTE: Entries are standardized beta coefficients. SDO = social dominance orientation.

$\dagger p<.10 . * p<.05 . * * p<.01 . * * * p<.001$.

in the figure, both subordinate groups had a tendency to think of affirmative action in the least objectionable ways (i.e., as training and outreach) rather than in the most objectionable ways (i.e., rather than as quotas or preferences for less-qualified applicants). Whites, in contrast, showed a slight tendency to do the reverse-more often framing affirmative action in negative terms rather than positive terms. Furthermore, repeated measures analyses of variance for each racial/ethnic group revealed that these differences were statistically significant within each racial/ethnic group; that is, Whites: $F(5,720)=$ $4.98, p<.01, \eta=.18$; Latinos: $F(5,220)=2.28, p<.05, \eta=$ .22 ; Blacks: $F(5,630)=12.97, p<.01, \eta=.30$.

A slightly different perspective on the framing question was explored by regressing each type of affirmative action frame on a cluster of demographic factors (here, using the simple dominant/subordinate, or White/minority, distinction) as well as a cluster of political ideologies/social values, namely, political conservatism, belief that success is a function of one's individual merit, and social dominance orientation (see Table 1). Consistent with the picture one gets from Figure 2, net of all other factors, there was a general (but not always significant) tendency for Whites to eschew positive frames and embrace negative ones. With respect to the two neutral forms of affirmative action (i.e., tie-breaking and "one factor among many"), there were essentially no race/ ethnicity effects.

However, it is also noteworthy that there were relatively weak relationships between the demographic and sociopolitical variables and tendencies to use particular affirmative action frames. Although there was no dramatic difference in the amount of variance accounted for across the different frames, the data seem to suggest

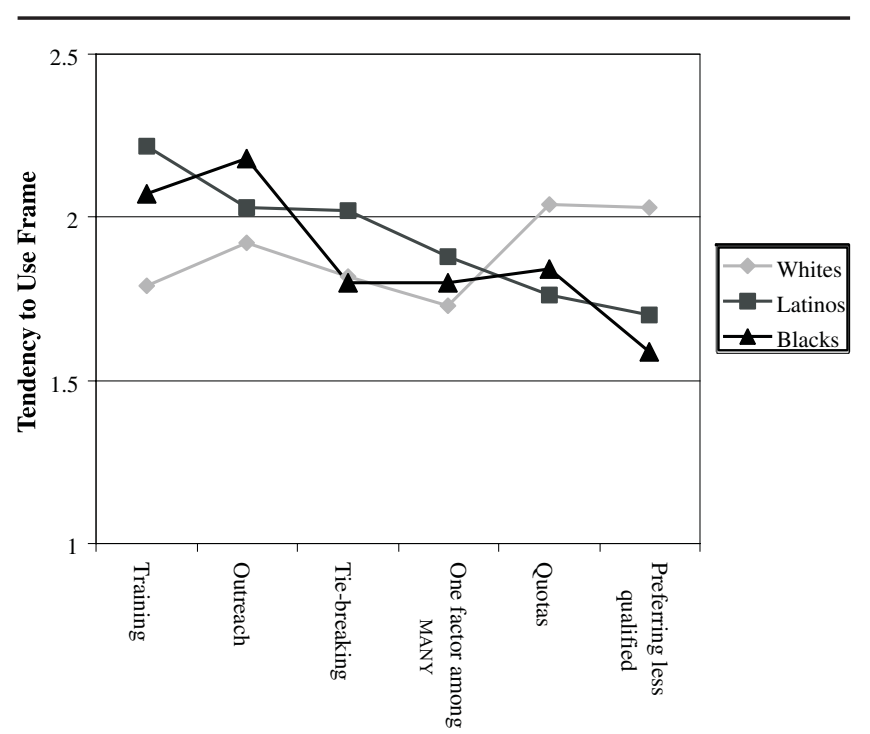

Affirmative Action Frame (least opposed - most opposed)

Figure 2 Mean tendency to use each of six different affirmative action frames, by respondent race/ethnicity.

that tendencies to use the most negative affirmative action frames (i.e., quotas and preferences for less-qualified candidates) are slightly better accounted for than are tendencies to use the other four frames. In particular, the tendency to frame affirmative action in the most negative way (i.e., preferences for less-qualified candidates) was better accounted for than any other (adjusted $\left.R^{2}=.12, p<.001\right)$ and also more powerfully accounted for by the ideological/value dimensions of SDO $(\beta=.15$, $p<.05)$ and political conservatism $(\beta=.14, p<.05)$. 
Finally, in addition to examining framing tendencies one frame at a time, we examined people's overall tendencies to use negative rather than positive frames. To do this, we constructed a variable that reflects the relationship between (a) the degree to which a given individual opposed a particular frame and (b) the degree to which that same individual tended to use that frame when thinking about affirmative action. This variable was constructed by determining the correlation $(r)$ between (a) and (b) above for each individual.

In other words, suppose that the values for a given person's opposition to each of six affirmative opposition frames were $\mathrm{X}_{1}, \mathrm{X}_{2}, \mathrm{X}_{3}, \mathrm{X}_{4}, \mathrm{X}_{5}$, and $\mathrm{X}_{6}$, and suppose that same person, when asked how often he or she tended to think of affirmative action in each of these ways, gave the responses $\mathrm{Y}_{1}, \mathrm{Y}_{2}, \mathrm{Y}_{3}, \mathrm{Y}_{4}, \mathrm{Y}_{5}$, and $\mathrm{Y}_{6}$. We then simply computed the product-moment correlation between the Xs and the Ys for each individual participant. When this correlation is positive, it indicates that a person chooses to frame affirmative action in ways that he or she finds especially disturbing or offensive. When this correlation is negative, on the other hand, it indicates that a person tends to choose frames that he or she finds most appealing, or flattering. Because positive values here reflect tendencies to use the frames that are viewed most negatively, we refer to this correlation coefficient as the negative framing index (NFI). ${ }^{3}$

It should be understood that the NFI, although strongly related to general (positive or negative) attitudes toward affirmative action, is a distinct construct. Indeed, this distinctiveness is evidenced by the fact that the product-moment correlation between one's general opposition to affirmative action (not defined in any particular way) and the NFI was a healthy .51, indicating that approximately $74 \%$ of the variance of the NFI can still not be accounted for by general opposition to affirmative action.

Inspection of descriptive statistics for the NFI index revealed an overall arithmetic average of -.128 $(S D=$ $.503)$. Thus, in general, people had a mild tendency to frame affirmative action in terms that they found relatively positive. Nonetheless, there is strong reason to expect that this framing behavior will depend on race/ethnicity, among other things. As a first pass at this question, we performed one-sample $t$ tests within each of the three racial/ethnic groups against the null hypothesis that the population framing index was 0.00 (i.e., against the hypothesis that there was neither a tendency to use positively viewed frames nor a tendency to use negatively viewed frames). The results of these analyses showed that both Blacks and Latinos had a tendency to use frames that they personally believed to be relatively favorable (for the two-tailed tests, Blacks: $M=-.286, S D=.442$, $t=-7.35, d f=128, p=.001$; Latinos: $M=-.120, S D=.479$, $t=-1.74, d f=47, p=.09)$. In contrast, and somewhat surprisingly, the NFI for Whites was not significantly different from zero, indicating that, on average and as a group, Whites showed no overall tendency to frame affirmative action in either terms that they felt were positive or terms that they felt were negative $(M=.005, S D=.524$, $t<1, d f=151, n s)$.

\section{The Determinants of Negative Affirmative Action Framing: A Causal Analysis}

Having examined racial/ethnic differences in perceptions of different affirmative action frames, and racial/ethnic differences in tendencies to use particular types of frames, our analysis next moved beyond questions of race/ethnicity to examine some of the sociopolitical/ideological underpinnings of framing tendencies. As will be recalled, within the motivated social cognition perspective (e.g., Jost et al., 2003), we should expect an NFI difference not just with respect to race/ ethnicity but also with respect to conservative beliefs (e.g., political conservatism and the belief that success is primarily due to individual merit).

Social dominance theory also would lead us to expect an NFI difference with respect to SDO. More specifically, it suggests that in addition to indirectly affecting the NFI via conservative beliefs, SDO should have significant direct effects of its own. In this analysis, we therefore compare the usefulness of the conservatism and social dominance models in predicting the tendency to frame affirmative action in ways that one personally sees as negative rather than positive.

In doing so, we employed structural equation modeling (using LISREL 8.54) with the variance-covariance matrix as input and maximum likelihood estimation of all parameters. We will first explore here what we call the conservatism model, where the tendency to frame affirmative action in negative terms (i.e., the NFI) is predicted by political conservatism, the belief that success is due to individual merit, and race/ethnicity. This conservatism model will then be compared with the social dominance model, which adds SDO as a direct and indirect predictor. In both of these analyses, we will take account of basic demographic variables and operationalize respondent race/ethnicity with a simple dichotomous distinction (Whites $=1$, minorities $=0$ ).

The standardized path coefficients for the conservatism model are shown in Figure 3. Consistent with the assumptions of this model, race/ethnicity, belief that one's success is a function of individual merit, and political conservatism were all found to make significant net contributions to the tendency to frame affirmative action in negative terms $(\gamma=.19, p<.05, \beta=.12, p<.05$, and $\beta=.25, p<.05$, respectively). Furthermore, inspection of 


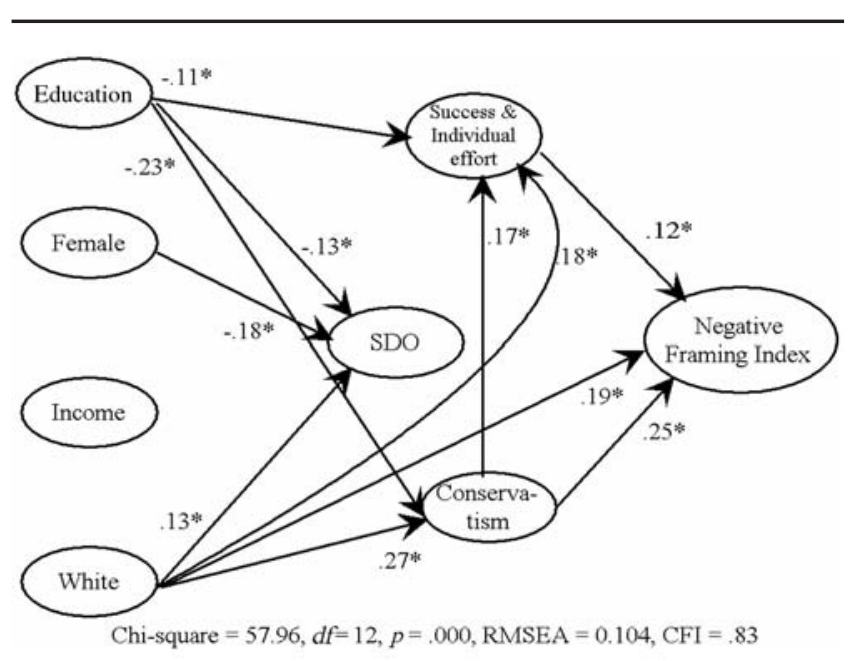

Figure 3 Structural equation model of the predictors of participants' "negative framing index": Conservatism model.

NOTE: $\mathrm{SDO}=$ social dominance orientation, $\chi^{2}=57.96, d f=12, p=$ .000 , root mean square error of approximation (RMSEA) $=0.104$, Comparative Fit Index $(\mathrm{CFI})=.83$.

$* p<.05$.

the LISREL output disclosed that race/ethnicity made significant direct contributions to the NFI as well as significant indirect contributions via the tendency for Whites to be more politically conservative $(\gamma=.27, p<$ $.05)$ and the tendency for Whites to be more likely to believe that one's success is largely a function of individual merit $(\gamma=.18, p<.05$; indirect effect $=.07, p<.01) .{ }^{4}$ Nonetheless, despite these theoretically consistent results, the conservatism model did not provide a satisfactory fit to the data overall (i.e., $\chi^{2}=57.96, d f=12, p<.000$, root mean square error of approximation $[$ RMSEA] $=.104$, Comparative Fit Index $[\mathrm{CFI}]=.83$ ).

We therefore estimated the social dominance model, in which SDO was allowed to have both direct and indirect effects on the NFI (via its associations with both political conservatism and belief in individual merit; see Figure 4). Because the social dominance model is nested within the conservatism model, we were first able to determine whether the social dominance model provides a significant increase in model fit. With the loss of only 3 degrees of freedom we were able to improve the model fit by some 47.22 chi-square units. This was indeed a statistically significant increase in model fit $\left(p<10^{-5}\right)$. Not only did this social dominance model significantly improve model fit but the overall level of fit of the model to the data was quite strong $\left(\chi^{2}=10.74, d f=9, p<.29\right.$, RMSEA $=.024, \mathrm{CFI}=.99)$. In addition, inspection of the path coefficients in Figure 4 showed, as anticipated, that SDO made a statistically significant net contribution to the tendency to frame affirmative action in negative terms $(\beta=.18, p<.05)$. Furthermore, also consistent with

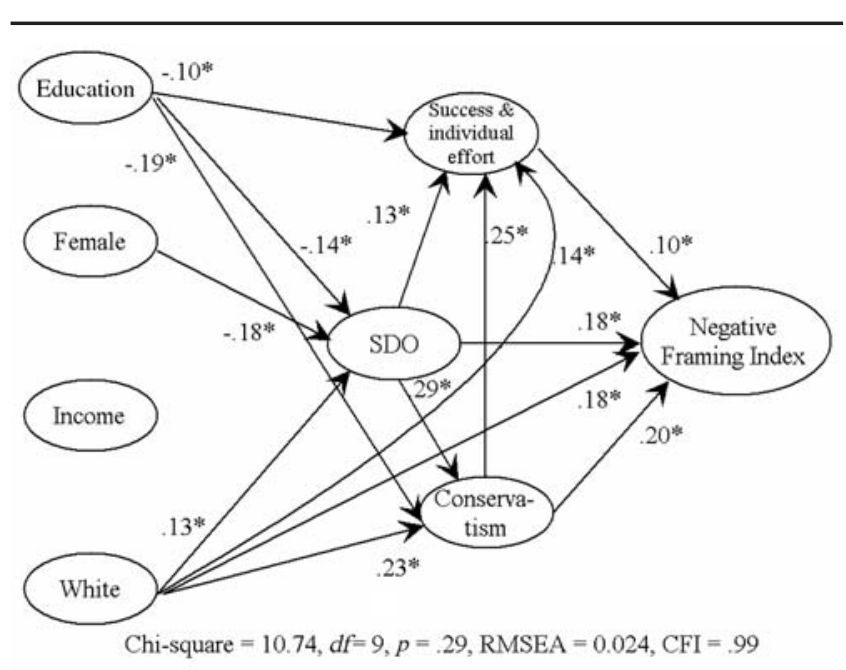

Figure 4 Structural equation model of the predictors of participants' "negative framing index": Social dominance model.

NOTE: $\mathrm{SDO}=$ social dominance orientation, $\chi^{2}=10.74, d f=9, p=.29$, root mean square error of approximation (RMSEA) $=0.024$, Comparative Fit Index $(\mathrm{CFI})=.99$.

$* p<.05$.

the general reasoning of social dominance theory, SDO made statistically significant indirect contributions to the NFI via the mediated effects of both political conservatism and belief in individual merit (indirect effect $=$ $.07, p<.01)$. Finally, it should be noted that the indirect effects of race/ethnicity on the NFI were every bit as strong as in the conservatism model (indirect effect = $.08, p<.01)$.

\section{DISCUSSION}

This research has sought to deepen existing knowledge about how people perceive affirmative action when it is framed in different ways, how people typically frame affirmative action when thinking about it on their own, and what factors are predictive of people's tendencies to use particular (positive vs. negative) frames. This research also has sought to examine whether and how respondent race/ethnicity might interact with frame perceptions and with tendencies to use particular frames. In this research, we employed a survey methodology to obtain responses from a large sample of White, Latino, and Black adults. The frames we studied included those most commonly represented in the public discourse: providing training to certain groups, engaging in outreach to recruit members of certain groups, considering group membership as "one factor among many," using group membership as a "tie-breaking" device, using quotas, and giving preferences to (relatively) underqualified applicants.

Our results indicated, in line with previous research (e.g., Bell et al., 2000; Bobo \& Kluegel, 1993; Bobo \& 
Smith, 1994; Fine, 1992; Kinder \& Sanders, 1990; Kravitz, 1995; Schuman et al., 1997; Sniderman \& Carmines, 1997; Summers, 1995), that opposition to affirmative action is an extraordinarily pliable attitude, significantly dependant on framing. As expected, respondents of all races/ethnicities showed rather strong opposition to the same frames (seeing quotas and preferences for relatively underqualified applicants as relatively objectionable) and rather weak opposition to the same frames (seeing training and outreach initiatives as relatively acceptable). However, also as anticipated, Whites were consistently more opposed to affirmative action than were the other groups, regardless of framing. Indeed, our analysis revealed that even framing affirmative action in the most acceptable terms did essentially nothing to attenuate racial/ethnic differences in affirmative action opposition.

Racial/ethnic divergences were further apparent when tendencies to use particular frames were examined. Our results indicated that compared to Whites, Latinos and Blacks tend to think of affirmative action in flattering rather then unflattering terms. Thus, not only was there evidence that different people tend to use different frames but there also was evidence that framing tendencies varied across respondents in a systematic rather than random way (Golden et al., 2001; Kravitz et al., 2000; Kravitz \& Klineberg, 2000), in this case, along racial/ethnic lines. Sniderman, Crosby, and Howell (2000) recently argued that

given the genuine variety of proposals falling under the overall tent of government actions dealing with race, citizens may, and likely will, take different positions as to what government should do regarding race, just so far as they are being asked to approve different courses of action. (p. 238)

We concur, although these results also compel us to add that people are not always passive (or objective) recipients of policy information but are instead often active in constructing and deploying particular definitions of social policy, definitions that can serve to reinforce particular views and to bias perceptions of new information.

Using the motivated social-cognitive perspective as a guiding framework, we also examined some of the sociopolitical/ideological motivations underpinning people's tendencies to use negative rather than positive frames. Based on structural equation modeling, we found that the theoretical model derived from social dominance theory was superior to the simpler conservatism model. In the conservatism model, in addition to demographic variables, just two variables (which were themselves expected to be related) were predicted to affect the negative framing index: political conservatism and support for the idea that success in U.S. society is a function of individual merit. Despite the fact that the predicted paths were indeed found, this model provided, overall, a rather poor fit to the data.

The social dominance model was identical to this first model except that it also expected a direct effect of SDO on negative framing, direct effects of SDO on conservative beliefs (political conservatism and support for the notion that success is a function of individual merit), and-finally-indirect effects of SDO on negative framing via its association with these conservative beliefs. This social dominance model provided an excellent fit to the data, indicating that high levels of SDO powerfully influence people's tendencies to think of and use the most damning frames of affirmative action they can. This finding is consistent with research showing the utility of dominance motives-above and beyond other ideological and attitudinal variables-in predicting simple opposition to affirmative action (e.g., Federico \& Sidanius, 2002), and it adds to that research by indicating that the social dominance perspective can significantly account for how people actively construct (evaluative) frames of affirmative action that can be used to reinforce and perpetuate preexisting attitudes.

The notion that people form schemas, or frames, for issues such as affirmative action is not new (e.g., Nacoste, 1994; Nacoste \& Hummels, 1994). In fact, there have been important hints in the literature about precisely what kinds of assumptions people's affirmative action frames tend to include. For example, research conducted by Heilman, Battle, Keller, and Lee (1998), using a mixed-sex sample of undergraduate and MBA students, found that-unless they were told otherwisestudents' behaviors suggested that they assumed that female-targeted affirmative action programs stipulated that an applicant's merit be a peripheral consideration (rather than a central one). Other research (Arriola \& Cole, 2001; Golden et al., 2001) has indicated that many people automatically assume that affirmative action policies involve "quotas" or "preferential treatment." Our research adds to this stream of literature by empirically demonstrating that people's tendencies to frame affirmative action in particular ways are probably motivated (by SDO) rather than being arbitrary or stochastic; that is, our research indicates that the tendency to use frames that are viewed as objectionable rather than acceptable is, in part, driven by people's desires to maintain and/or fortify existing group-based hierarchy.

Our research also has practical implications. It suggests, similar to past research (e.g., Kinder \& Sanders, 1990), that policy makers, employers, and others who desire to change people's (positive or negative) attitudes toward affirmative action should employ and encourage the use of certain frames as opposed to others. In addi- 
tion, however, our research suggests that the link between affirmative action attitudes and dominance motives needs to be kept in mind and that policy makers and employers will not be able to eliminate group differences in affirmative action attitudes so facilely. Indeed, regardless of how affirmative action information is presented to people, it appears that people absorb such information only through the filter of (group-dominancerelated) preexisting assumptions.

Some researchers have suggested that an unearthing and clarification of people's different assumptions could help to build consensus among affirmative action supporters and detractors. For example, Golden et al. (2001) have suggested,

Honest and open dealing [with the issue of affirmative action] must surely begin with a clear exposition of the terms of the debate. When clear definitions are agreed upon, the distance between the supporters and the opponents of affirmative action may decrease. (p. 83)

Our results cast doubt on this idea, however, given that significant racial/ethnic differences in support for affirmative action persisted across each and every frame we examined, and given that the frames guiding people's thinking about affirmative action are so intimately yoked to broader ideological and attitudinal variables. In sum, despite the fact that people evaluate affirmative action very differently depending on how it is framed, it seems clear that they seize and deploy those frames that best complement their level, dominance-related motives.

\section{NOTES}

1. These basic conclusions held even after family income, age, education, and gender served as covariates.

2. Controlling for income, age, education, and gender eliminated the main effect of affirmative action type but left all other effects essentially the same.

3. Specifically, imagine the following data matrix. The negative framing index (NFI) is simply the correlation between vectors $\mathrm{X}$ and $\mathrm{Y}$.

\begin{tabular}{lcc}
\hline & & Tendency to \\
& & Think of \\
& Disapproval & Affirmative \\
of $a$ & Action in \\
& Particular & Terms of $a$ \\
& Affirmative & Particular \\
Action Frame & Frame \\
Type of Affirmative Action & $\mathrm{X}_{1}$ & $\mathrm{Y}_{1}$ \\
Training & $\mathrm{X}_{2}$ & $\mathrm{Y}_{2}$ \\
Outreach & $\mathrm{X}_{3}$ & $\mathrm{Y}_{3}$ \\
Tie-breaking & $\mathrm{X}_{4}$ & $\mathrm{Y}_{4}$ \\
"One factor among many" & $\mathrm{X}_{5}$ & $\mathrm{Y}_{5}$ \\
Quotas & & \\
Preferences for less-qualified & $\mathrm{X}_{6}$ & $\mathrm{Y}_{6}$ \\
applicants & & \\
\hline
\end{tabular}

4. These mediational tests in LISREL are essentially equivalent to the common Sobel procedure used in connection with least-squares regression (e.g., see Kaplan, 2000, pp. 35-36).

\section{REFERENCES}

Aberson, C. L., \& Haag, S. C. (2003). Beliefs about affirmative action and diversity and their relationship to support for hiring policies. Analyses of Social Issues and Public Policy, 3(1), 121-138.

Arriola, K. R. J., \& Cole, E. R. (2001). Framing the affirmative-action debate: Attitudes toward out-group members and White identity. Journal of Applied Social Psychology, 31(12), 2462-2483.

Bell, M. P., Harrison, D. A., \& McLaughlin, M. E. (2000). Forming, changing, and acting on attitudes toward affirmative action programs in employment: A theory-driven approach. Journal of Applied Psychology, 85(5), 784-798.

Blumer, H. (1958). Racial prejudice as a sense of group position. Pacific Sociological Review, 1, 3-7.

Bobo, L. D., Johnson, J. H., Oliver, M. L., Sidanius, J., \& Zubrinsky, C. (1992). Public opinion before and after a spring of discontent: A preliminary report on the 1992 Los Angeles County Social Survey (1992-1993, Vol. 3, No. 1). Los Angeles: UCLA Center for the Study of Urban Poverty.

Bobo, L., \& Kluegel, J. R. (1993). Opposition to race-targeting: Selfinterest, stratification ideology, or racial attitudes? American Sociological Review, 58(4), 443-464.

Bobo, L., \& Smith, R. A. (1994). Antipoverty policies, affirmative action, and racial attitudes. In S. H. Danziger, G. D. Sandefur, \& D. H. Weinberg (Eds.), Confronting poverty: Prescriptions for change (pp. 365-395). Cambridge, MA: Harvard University Press.

Bobo, L. (1999). Prejudice as group position: Microfoundations of a sociological approach to racism and race relations. Journal of Social Issues, 55, 445-472.

Borowiak, A., \& Golec, A. (2004). Poznawcze i swiatopogladowe wyznaczniki preferencji politycznych [Motivated cognition and cultural worldviews as predictors of political preferences]. Studia Psychologiczne, 42(2), 5-16.

Duckitt, J. (2001). A dual-process cognitive-motivational theory of ideology and prejudice. Advances in Experimental Social Psychology, 33, 41-113.

Dunning, D. (1999). A newer look: Motivated social cognition and the schematic representation of social concepts. Psychological Inquiry, 10, 1-11.

Fazio, R. H. (1990). Multiple processes by which attitudes guide behavior: The MODE model as an integrative framework. In M. P. Zanna (Ed.), Advances in experimental social psychology (Vol. 23, pp. 75-109). San Diego, CA: Academic Press.

Federico, C. M., \& Sidanius, J. (2002). Racism, ideology, and affirmative action revisited: The antecedents and consequences of "principled objections" to affirmative action. Journal of Personality $\mathcal{E}$ Social Psychology, 82(4), 488-502.

Fine, T. S. (1992). The impact of issue framing on public opinion: Toward affirmative action programs. Social Science Journal, 29(3), 323-334.

Fiske, S. T., \& Taylor, S. E. (1991). Social cognition (2nd ed.). New York: McGraw-Hill.

Fraser, J., \& Kick, E. (2000). The interpretive repertoires of Whites on race-targeted policies: Claims making of reverse discrimination. Sociological Perspectives, 43(1), 13-28.

Golden, H., Hinkle, S., \& Crosby, F. (2001). Reactions to affirmative action: Substance and semantics. Journal of Applied Social Psychology, 31, 17-32.

Greenwald, A. G. (1980). The totalitarian ego: Fabrication and revision of personal history. American Psychologist, 35, 603-618.

Greenwell, M., Strohm, M., \& Bobo, L. (1994). Project memoranda: Nonresponse bias evaluation. Los Angeles: University of California Pres.

Heilman, M. E., Battle, W. S., Keller, C. E., \& Lee, R. A. (1998). Type of affirmative action policy: A determinant of reactions to sex-based preferential selection? Journal of Applied Psychology, 83, 190-205.

Jackman, M. R. (1994). The velvet glove: Paternalism and conflict in gender, class, and race relations. Berkeley: University of California Press. 
Jost, J. T., Glaser, J., Kruglanski, A. W., \& Sulloway, F. J. (2003). Political conservatism as motivated social cognition. Psychological Bulletin, 129(3), 339-375.

Kaplan, D. (2000). Structural equation modeling. Foundations and extensions. Thousand Oaks, CA: Sage.

Kinder, D. R., \& Sanders, L. M. (1990). Mimicking political debate with survey questions: The case of White opinion on affirmative action for Blacks. Social Cognition [Special Issue: Thinking about politics: Comparisons of experts and novices], 8(1), 73-103.

Kinder, D. R., \& Sanders, L. M. (1996). Divided by color: Racial politics and democratic ideals. Chicago: University of Chicago Press.

Kluegel, J. R., \& Smith, E. R. (1986). Beliefs about inequality: Americans' views of what is and what ought to be. Hawthorne, NY: Aldine de Gruyter.

Kravitz, D. A. (1995). Attitudes toward affirmative action plans directed at blacks: Effects of plan and individual differences. Journal of Applied Social Psychology, 25(24), 2192-2220.

Kravitz, D. A., \& Klineberg, S. L. (2000). Reactions to two versions of affirmative action among Whites, Blacks, and Hispanics. Journal of Applied Psychology, 85(4), 597-611.

Kravitz, D. A., Klineberg, S. L., Avery, D. R., Nguyen, A. K., Lund, C., \& Fu, E. J. (2000). Attitudes toward affirmative action: Correlations with demographic variables and with beliefs about targets, actions, and economic effects. Journal of Applied Social Psychology, 30(6), 1109-1136.

Kunda, Z. (1990). The case for motivated reasoning. Psychological Bulletin, 108, 480-498.

Murrell, A. J., Dietz-Uhler, B. L., Dovidio, J. F., Gaertner, S. L., \& Drout, C. (1994). Aversive racism and resistance to affirmative action: Perceptions of justice are not necessarily color blind. Basic E A Applied Social Psychology, 15(1-2), 71-86.

Nacoste, R. W. (1994). Policy schemas for affirmative action. In L. Heath \& R. S. Tindale (Eds.), Applications of heuristics and biases to social issues: Social psychological applications to social issues (Vol. 3, pp. 205-221). New York: Plenum.

Nacoste, R. W., \& Hummels, B. (1994). Affirmative action and the behavior of decision makers. Journal of Applied Social Psychology, 24(7), 595-613.

O'Neil, M. J. (1979). Estimating the non-response bias due to refusals in telephone surveys. Public Opinion Quarterly, 43, 218-232.

Pratto, F., Sidanius, J., Stallworth, L. M., \& Malle, B. F. (1994). Social dominance orientation: A personality variable predicting social and political attitudes. Journal of Personality and Social Psychology, 67(4), 741-763.

Quinn, K. A., Ross, E. M., \& Esses, V. M. (2001). Attributions of responsibility and reactions to affirmative action: Affirmative action as help. Personality EO Social Psychology Bulletin, 27(3), 321-331.

Redlawsk, D. P. (2002). Hot cognition or cool consideration? Testing the effects of motivated reasoning on political decision making. Journal of Politics, 64(4), 1021-1044.

Schuman, H., Steeh, C., Bobo, L., \& Krysan, M. (1997). Racial attitudes in America: Trends and interpretations (Rev. ed.). Cambridge, MA: Harvard University Press.
Sherif, M. (1966). In common predicament: Social psychology of intergroup conflict and cooperation. New York: Houghton Mifflin.

Sidanius, J. (1993). The psychology of group conflict and the dynamics of oppression: A social dominance perspective. In S. Iyengar \& W. J. McGuire (Eds.), Explorations in political psychology: Duke studies in political psychology (pp. 183-219). Durham, NC: Duke University Press.

Sidanius, J., Levin, S., Federico, C., \& Pratto, F. (2001). Legitimizing ideologies: The social dominance approach. In J. Jost \& B. Major (Eds.), The psychology of legitimacy: Emerging perspectives on ideology, justice, and intergroup relations (pp. 307-331). London: Cambridge University Press.

Sidanius, J., Liu, J., Shaw, J., \& Pratto, F. (1994). Social dominance orientation, hierarchy-attenuators and hierarchy-enhancers: Social dominance theory and the criminal justice system. Journal of $A p$ plied Social Psychology, 24, 338-366.

Sidanius, J., \& Pratto, F. (1999). Social dominance: An intergroup theory of social hierarchy and oppression. New York: Cambridge University Press.

Sidanius, J., Pratto, F., \& Bobo, L. (1996) . Racism, conservatism, affirmative action, and intellectual sophistication: A matter of principled conservatism or group dominance? Journal of Personality and Social Psychology, 70(3), 476-490.

Sidanius, J., Singh, P., Hetts, J. J., \& Federico, C. (2000). It's not affirmative action, it's the Blacks: The continuing relevance of race in American politics. In D. O. Sears, J. Sidanius, \& L. Bobo (Eds.), Racialized politics: The debate about racism in America (pp. 191-235). Chicago: University of Chicago Press.

Sniderman, P. M., \& Carmines, E. G. (1997). Reaching beyond race. PS: Political Science and Politics, 30(3), 466-471.

Sniderman, P. M., Crosby, G. C., \& Howell, W. G. (2000). The politics of race. In D. O. Sears, J. Sidanius, \& L. Bobo (Eds.), Racialized politics: The debate about racism in America (pp. 236-279). Chicago: University of Chicago Press.

Sniderman, P. M., \& Piazza, T. (1993). The scar of race. Cambridge, MA: Harvard University Press.

Son Hing, L. S., Bobocel, D. R., \& Zanna, M. P. (2002). Meritocracy and opposition to affirmative action: Making concessions in the face of discrimination. Journal of Personality E Social Psychology, 83(3), 493-509.

Summers, R. J. (1995). Attitudes toward different methods of affirmative action. Journal of Applied Social Psychology, 25(12), 1090-1104.

van den Berghe, P. L. (1967). Race and racism. New York:John Wiley.

Wetherell, M., \& Potter, J. (1992). Mapping the language of racism: Discourse and the legitimation of exploitation. New York: Columbia University Press.

Received March 10, 2005

Revision accepted September 1, 2005 